\title{
Elite capture, political voice and exclusion form aid: an experimental study
}

Citation for published version (APA):

d'Exelle, B., \& Riedl, A. M. (2008). Elite capture, political voice and exclusion form aid: an experimental study. METEOR, Maastricht University School of Business and Economics. METEOR Research Memorandum No. 024 https://doi.org/10.26481/umamet.2008024

Document status and date:

Published: 01/01/2008

DOI:

10.26481/umamet.2008024

Document Version:

Publisher's PDF, also known as Version of record

\section{Please check the document version of this publication:}

- A submitted manuscript is the version of the article upon submission and before peer-review. There can be important differences between the submitted version and the official published version of record.

People interested in the research are advised to contact the author for the final version of the publication, or visit the DOI to the publisher's website.

- The final author version and the galley proof are versions of the publication after peer review.

- The final published version features the final layout of the paper including the volume, issue and page numbers.

Link to publication

\footnotetext{
General rights rights.

- You may freely distribute the URL identifying the publication in the public portal. please follow below link for the End User Agreement:

www.umlib.nl/taverne-license

Take down policy

If you believe that this document breaches copyright please contact us at:

repository@maastrichtuniversity.nl

providing details and we will investigate your claim.
}

Copyright and moral rights for the publications made accessible in the public portal are retained by the authors and/or other copyright owners and it is a condition of accessing publications that users recognise and abide by the legal requirements associated with these

- Users may download and print one copy of any publication from the public portal for the purpose of private study or research.

- You may not further distribute the material or use it for any profit-making activity or commercial gain

If the publication is distributed under the terms of Article $25 \mathrm{fa}$ of the Dutch Copyright Act, indicated by the "Taverne" license above, 
Ben D’Exelle, Arno Riedl

Elite Capture, Political Voice and Exclusion from Aid: An Experimental Study

$\mathrm{RM} / 08 / 024$

JEL code: D72, C91

\section{METE@R}

Maastricht research school of Economics of TEchnology and ORganizations

Universiteit Maastricht

Faculty of Economics and Business Administration P.O. Box 616

NL - 6200 MD Maastricht

phone : ++31433883830

fax : ++31433884873 


\title{
Elite Capture, Political Voice and Exclusion from Aid: An Experimental Study ${ }^{\text {II }}$
}

\author{
Ben D'Exelle* and Arno Riedl ${ }^{* *}$
}

July 2008

\begin{abstract}
We experimentally study the influence of local information conditions on elite capture and social exclusion in community-based development schemes with heterogeneous groups. Not only information on the distribution of aid resources through communitybased schemes, but also information on who makes use of an available punishment mechanism through majority voting may be important. The main results are the following. First, many rich community representatives try to satisfy a political majority who would then abstain from using the punishment mechanism, and exclude those community members whose approval is then not required. The frequency of this exclusion strategy is highest with private information on the distribution and public voting. Second, when voting is public, responders are more reluctant to make use of the punishment mechanism, and representatives who follow the exclusion strategy are more inclined to exclude the poorest responder. Third, punishment is largely ineffective as it induces rich representatives to capture all economic resources. Fourth, if a poor agent takes the representative's role, punishment rates drop, efficiency increases, and final distributions become more equal.
\end{abstract}

\section{JEL classification: D72, C91}

Keywords: Distribution of aid; Inequality; Social exclusion; Laboratory experiment

\footnotetext{
${ }^{*}$ University of Antwerp, IOB, Stadscampus, Lange Sint Annastraat 7, 2000 Antwerp, Belgium (corresponding author)

** CESifo, IZA, and Maastricht University, Department of Economics (AE1), P.O. Box 616, 6200MD Maastricht, the Netherlands

II This paper is part of the research project 'Experimental analysis of the formation, dynamics and economic consequences of social networks' financed by the Oesterreichische Nationalbank (project number 11429). The research documented in this work also benefited from the financial support of the Institute of Development Policy and Management at the University of Antwerp. We are also grateful to participants of the Behavioral and Experimental Economics group meetings of Maastricht University who helped us to improve the experimental design and Martin Strobel for his advice on Z-tree programming.
} 


\section{Introduction}

An increasing number of government and non-government aid programs follow a community-based development approach. According to conservative calculations, the World Bank's portfolio of projects that follow such an approach has increased from \$325 million in 1996 to \$2 billion in 2003 (Mansuri and Rao, 2004). In practice, this approach amounts to giving community representatives a formal mandate to distribute aid resources among the community members. This has several advantages. In comparison with the officers of aid programs, local representatives tend to have better access to local information, which might increase the efficiency and effectiveness of the program.

It is, however, not evident that these representatives - generally among the better-off community members (Bierschenk et al. 2000; Platteau and Gaspart, 2003; Mansuri and Rao, 2004) - have similar interests as the aid donors, mainly concerned with the fate of the poorest. In comparison with aid donors, these representatives are not necessarily driven by 'social preferences' but also by individual profit motives. The advantages of delegating distribution tasks to local representatives may therefore be jeopardized by increasing elite capture and social exclusion (Alderman, 2001; Galasso and Ravallion, 2001; Conning and Kevane, 2002; Platteau and Abraham, 2002; Platteau and Gaspart, 2003; Mansuri and Rao, 2004). At the same time, however, potential beneficiaries are not passive agents. Very often they have the ability to influence the distributive decision of the representative by making use of political voice and control mechanisms. These mechanisms ${ }^{1}$, however, do not automatically enable community members to make representatives accountable to them. The following elements are important to consider.

First, it may be a deliberate strategy of representatives to undermine any political coalition that obliges them to retain fewer resources. They can do so by satisfying a political majority who would then abstain from using the political voice and control mechanism, while excluding those community members whose approval is then not required. Exclusion may thus be implied by a representative's profit seeking.

Second, the effectiveness of political voice and control mechanisms might depend on the information flows among community members. Conning and Kevane (2002) in their review of community-based targeting schemes emphasize that a community's ability to mobilize information could influence opportunities for capture by elites. Similarly, Abraham and Platteau (2004) argue that rural elites in African communities are often able to benefit themselves because of poor flows of information.

1 The availability of these mechanisms should not be taken for granted. In traditional African societies, for instance, decisions tend to be made through consensus-seeking, which makes it practically impossible for individual community agents to oppose the elite. Majority voting procedures to challenge community representatives and more so if voting is secret, are not accepted. To the extent that these close-knit societies become increasingly integrated in markets, leading to expanding opportunities and socio-economic differentiation, community members acquire more freedom to disagree with the ruling elite (Platteau and Abraham, 2002). This characterizes the current situation of most Latin American and Asian communities. In these societies, political voice and control mechanisms tend to be readily available. 
Two types of information are particularly important. Access to information on the distribution of the aid resources might influence community members' use of political control mechanisms. Information on who disagrees with the proposed distribution and makes use of the political control institution might also matter. If the latter information is made public (e.g. through a quick hand raising procedure instead of an anonymous voting procedure), community members may take this into account when making their decisions. In particular, it is plausible that, in a repeated setting, community members who express dissatisfaction may receive less from the representative and thus eventually become worse-off in comparison with those who remain silent. Responders who disagree with the distribution may anticipate this and therefore refrain from expressing dissatisfaction if voting is public.

To examine the influence of these information conditions on elite capture and social exclusion by the representative, and the voice of community members as potential beneficiaries of these resources, we organized a laboratory experiment. Experimental methods are increasingly used in development economics (Cason and Khan, 1999; Cardenas, 2003; Karlan, 2005; Cardenas and Carpenter, 2008) and they are particularly useful to study behavioral dimensions at work when distributive decisions are made. Moreover, different institutions can be created in a controlled way, so that the influence of diverse institutional arrangements on individual behavior can be studied; something which is very difficult or impossible in an uncontrolled real-life environment (Ostrom, 1998: 17). A strong advantage of conducting laboratory experiments relates to the control of the data gathering process. Information is acquired in a systematic way, so that noise is minimized, and more complex experiments can be conducted (e.g. repeated play, multiple participants, etc.). Some disadvantages, however, remain which will be addressed in the discussion section.

In our experiment, a permanent representative, being the richest of an economically heterogeneous group, is asked to distribute a fixed amount of resources among the group members in subsequent rounds ${ }^{2}$. After each distribution decision, the other members have the possibility to punish the representative, but only if a majority of them votes in favor of doing so. To look at the influence of information about the distribution decisions made by the representative we compare a situation with public information on the complete distribution of the resources with a situation where the responders only know their individual share. To study the importance of information on the voting decisions, we compare a situation with secret voting with a situation where both the representative and the responders obtain complete information on the individual voting decisions.

The experimental results show that many representatives try to satisfy a political majority who would then abstain from voting in favor of punishment, while they exclude those community members whose approval is then not required. The frequency of this exclusion strategy is highest with private

2 Note the following two assumptions. First, it is the richest player who acts as representative. We justify this by the observation that most community representatives tend to be among the better-off. Second, the representative cannot be replaced. In most communities the local 'elite' although contested remains firmly in power. 
information on the distribution and public voting. When voting is public, responders are more reluctant to make use of the punishment mechanism, whereas representatives become aware that poorer responders are less reluctant to protest, so that these poorer responders are more likely excluded. Moreover, it is shown that punishment is ineffective in reducing elite capture or exclusion as, instead of enforcing representatives to reduce their share, it induces them to capture all economic resources in revenge. Finally, it is observed that if a poor agent takes the representative's role, punishment rates drop and final distributions become substantially more equal.

\section{Experimental design}

In this section, we describe the distribution game that we implemented in the laboratory. Its key elements are a multi-person distribution (dictator) game followed by a voting stage for punishment. We identify equilibria of the voting subgame under standard and social preferences and the resulting optimal strategies of the representative. Subsequently, we describe the procedures of the experiment, the parameters used in the experiment, and the treatment conditions.

\subsection{A non-cooperative distribution game with voting for punishment}

There are four players, labeled A, B, C and D, where player A assumes the role of representative. Each player has some endowment $E_{i}$, which can be interpreted as the players' wealth. Importantly, the endowments are unequally distributed among the players. The representative, $\mathrm{A}$, is assumed to be the richest, followed by the two responders $\mathrm{B}$ and $\mathrm{C}$; responder $\mathrm{D}$ is the poorest of all players (i.e. $E_{A}>E_{B}$ $\left.=E_{C}>E_{D}\right)$. The game proceeds as follows:

$\underline{\text { Stage 1: }}$ The representative, player A, distributes a fixed amount of resources $M$ among a group of four players, him/herself included, such that $x_{A}+x_{B}+x_{C}+x_{D}=M$, where $x_{i}$ indicates the share of player $i$.

Stage 2: The responders are informed about the distribution and simultaneously place a vote whether to punish the representative or not, that is each responder places a yes, $y$, or no, $n$, vote.

The (material) pay-offs of the players are determined in the following way. If less than two responders vote in favor of punishment everybody earns the amount according to the proposed distribution by the representative. On the other hand, if a majority of responders votes in favor of punishment the representative's payoff will be reduced by an amount $K$ and each responder's pay-off will be reduced by an amount $k$, where $K$ is assumed to be much larger than $k$.

The voting stage adds an important political-economic element to the distribution game. It can be interpreted as a control and punishment procedure implemented by the aid donor but also as a political instrument established endogenously in the community. We assume that such an institution already 
exists and investigate how important institutional details can affect a representative's distribution decision. In particular, we are interested in exclusionary practices by the representative. For this reason, there are three responders because then it is possible to exclude one responder when only a simple majority is needed in order to avoid punishment.

Our game bears some resemblance to two frequently studied games: the dictator game (e.g., Hoffman et al. 1994) and the ultimatum game (Güth et al., 1982). In the latter game, one player (the proposer) has to propose how to share a fixed amount of money with one responder. The responder can accept or reject the proposal, where upon rejection both players earn nothing. Experimental results typically are that the mean of the proposals is around $40 \%$ of the available amount and the mode is the equal split. At the same time, most offers of less than $20 \%$ are rejected by the responder (Camerer and Thaler, 1995; Henrich et al., 2004). ${ }^{3}$ Comparing these results with proposals made in dictator game experiments where the responder can only accept, distributors give more to the responder when the latter can punish by rejection (Hoffman et al., 1994). ${ }^{4}$

Our game differs in several aspects from the ultimatum and dictator game. First, the representative faces multiple responders that differ in economic wealth; second, punishment is not an individual decision but needs agreement via a political mechanism; third, in contrast to the ultimatum game the effect and cost of punishment are fixed.

In the following, we discuss theoretical predictions of our distribution game. We first characterize the pure strategy equilibria of the voting subgame assuming (common knowledge of) narrow material self-interest. Generally, since punishment is costly each responder prefers that the representative is not punished. However, whether the representative is punished or not also depends on the other responders' voting decision. When two other responders vote in favor of punishment, the third responder cannot change the voting outcome and is therefore indifferent between voting in favor or against punishment. If the third responder votes in favor of punishment, we obtain the strategy combination $(y, y, y)$, which is an equilibrium in weakly dominated strategies as any unilateral deviation leaves payoffs unchanged. However, if the third responder votes against punishment each of the other two responders can make himself better off by also voting against punishment. Consequently, a voting outcome with exactly two responders voting in favor of punishment cannot be an equilibrium. When no or exactly one responder votes in favor of punishment, the representative is not punished and no responder can make himself better off by a unilateral deviation. Therefore, the strategy

3 Assuming standard narrow selfish preferences and common knowledge of rationality, theory predicts that responders accept any positive amount and that proposers - anticipating this - offer the smallest possible positive amount. The actually observed behavior can be rationalized with recent models of inequity aversion (e.g. Fehr and Schmidt, 1999; Bolton and Ockenfels, 2000) and reciprocal fairness (e.g., Dufwenberg and Kirchsteiger, 2004; Falk and Fischbacher 2006).

4 The ultimatum game is also studied under a variety of extensions. The following are particularly interesting as they bear some resemblance to our distribution game. First, repeated pay with fixed partners (e.g. Slembeck, 1999) adds reputation considerations and tends to reduce the relative importance of fairness concerns. Second, in case of multiple responders, social comparison between responders becomes possible (Knez and Camerer, 1995; Riedl and Vyrastekova, 2004). 
combinations, $(y, n, n),(n, y, n),(n, n, y),(n, n, n)$ are also equilibria. It is worthwhile to note that the allocation decision of the representative is undetermined in equilibrium because any allocation of $M$ is sustainable as an equilibrium. ${ }^{5}$

In contrast to standard preferences where punishment reduces the utility of each player, with social preferences (e.g. Fehr and Schmidt, 1999; Bolton and Ockenfels, 2000) this can be different, as the responders' utility is influenced by social comparison with the representative. In the following, we assume that players have Fehr-Schmidt social preferences (Fehr and Schmidt, 1999). First note that due to the majority voting rule, $(y, y, y)$ and $(n, n, n)$ remain equilibria. If all responders take the same voting decision, no responder can change the outcome and hence, not increase his utility by changing his voting decision. For the other strategy combinations, $(y, n, n),(n, y, n),(n, n, y)$, which are equilibria with standard preferences we study under what conditions they are not longer equilibria with social preferences. For this to be the case, it is sufficient that at least two responders are better off when the representative is punished. In Proposition 1 (Appendix 2) we show that this is the case if the proposed allocation is sufficiently unequal and/or responders have a relatively strong aversion against disadvantageous inequality.

Due to the multiplicity of equilibria the representative's optimal strategy strongly depends on his beliefs about what equilibrium will be played. If the representative believes that the punishment outcome is independent from his/her distribution decision (e.g. because he/she expects that the responders will play $(y, y, y)$ or $(n, n, n))$, then the distribution game reduces to a dictator game. In Lemma 1 (Appendix 2) it is shown that the representative will follow the 'exclude-all'-strategy (i.e., keep all resources), if his aversion against advantageous inequality is not too strong. Otherwise, he will distribute the resources such that the final income of all players is equalized ${ }^{6}$.

If the representative believes that the punishment outcome is dependent on his distribution decision, he may want to avoid punishment. Proposition 2 (Appendix 2) identifies the representative's optimal strategy in this case. If the representative's aversion against advantageous inequality is very strong (i.e., guilt parameter is larger than $3 / 4$ ) then the optimal strategy is to equalize the final incomes of all players. In this case, all responders prefer the non-punishment outcome and equalizing income makes it likely that punishment is actually avoided. With a guilt parameter lower than $3 / 4$, the 'excludeall'-strategy is optimal if this strategy and any alternative strategy lead to the same punishment outcome. Proposition 2 identifies the conditions under which the 'exclude-one'-strategy can be optimal. For this strategy to be preferred to the 'exclude-all'-strategy it must hold that only the latter

5 To see this, consider an arbitrary allocation $\left(M-x_{B}-x_{C}-x_{D}, x_{B}, x_{C}, x_{D}\right)$ and voting strategies where all three responders vote against punishment when the allocation $\left(M-x_{B}-x_{C}-x_{D}, x_{B}, x_{C}, x_{D}\right)$ is offered and for punishment in any other case. Any unilateral deviation of the responders does not change the outcome, and hence the proposed voting strategies are equilibrium strategies in the voting subgame for any offered allocation. If the representative deviates and proposes an allocation different from $\left(M-x_{B}-x_{C}-x_{D}, x_{B}, x_{C}, x_{D}\right)$ he will be punished and loose $K$. Hence, it is strictly better not to deviate.

6 The latter is the case when the guilt parameter in the Fehr-Schmidt model is larger than 3/4, which is rarely observed (Fehr and Schmidt, 1999). 
strategy implies punishment. The 'exclude-one'-strategy may enable the representative to avoid punishment when it gives two responders a sufficiently high share such that they prefer nonpunishment. As the representative only needs two responders to abstain from voting for punishment to avoid punishment, he may increase his income by excluding the third responder. Profit-seeking representatives that follow the 'exclude-one'-strategy may look for responders that are satisfied with lower shares of the pie. In case of endowment inequality among the responders, it may therefore be an optimal strategy to exclude the poorest responder who may need more compensation in order to vote against punishment (see also Abbink and Ellman, 2005, for a reasoning along this line).

Due to the multiplicity of equilibria all discussed theoretical models give only limited guidance for what actual behavior we should expect. The models are also largely silent about the effects of changing institutional arrangements as information about the distribution decision and public versus secret voting procedures. It is, however, precisely these institutional arrangements we are interested in. Another shortcoming of the outcome-based models is that they do not satisfactorily take into account the possibility of responders being conditional cooperators in voting (Fischbacher et al., 2001; Fischbacher and Gächter, 2006). They may be more likely to vote in favor of punishment the more responders they believe will do as well. This would make $(y, y, y)$ a likely outcome. Since this strategy combination is also an equilibrium with standard and social preferences, empirical observation of this strategy combination alone does not tell us anything about its behavioral foundations. For this, we need to test for a correlation between a responder's propensity to vote in favor of punishment and his beliefs that the two other responders will do as well. The experiment we present below will give us answers to at least some of these questions.

\subsection{Experimental procedures and parameters}

At the beginning of an experimental session, participants are informed that the experiment consists of two independent parts and that the instructions for each part will be given after the previous part has been finished. In both parts, participants are matched in groups of four, which remain unchanged throughout both parts. In each part, participants play the previously described game for 10 subsequent rounds. At the beginning of each round, all players receive a fixed endowment. To induce economic inequality players receive different endowments. Person A receives 200 'francs' (high-endowment), players $\mathrm{B}$ and $\mathrm{C}$ receive 150 each (middle-endowment) and player D receives 100 (low-endowment). These player roles remain unchanged throughout both parts of the experiment. ${ }^{7}$

In each round of the first part of the experiment, the high-endowment player, who can be thought of being a permanent representative, is asked to distribute an additional (publicly known) 200 francs between all members. In the second part, the low-endowment player assumes this role. After each

\footnotetext{
Inequality is introduced before the start of the first round in a purely arbitrary way. The endowment each player receives at the beginning of each round is publicly known. The accumulated earnings of each participant are private knowledge throughout the experiment.
} 
distribution decision of the representative, responders are asked for their satisfaction (on a 9-point Likert scale) about their share received. Thereafter, they decide about placing a vote in favor or against punishing the representative. In case of punishment, the pay-off of the representative is reduced with 200 'francs ${ }^{8}$, whereas the cost of punishment is only 20 'francs' for each of the responders.

After each decision, participants are asked for their beliefs about the voting decisions of the responders. Each responder is asked for the likelihood that exactly two, one or none other responders vote in favor of punishment; and the representative is asked for the likelihood that the specific responders vote in favor of punishment. To induce sincere estimates we used the "quadratic scoring rule' for belief elicitation (see e.g. Offerman, 1997). ${ }^{9}$

We are interested in the effects of information about the distribution decision and the voting decision. Both conditions are particularly interesting because they are altered relatively easily by an aid donor $^{10}$ and have potentially important effects on the distribution and voting decisions. If information about the distribution remains private among the responders, social comparison processes are severely limited. Only when the distribution decision of the representative is fully disclosed, social comparison can enter the subsequent voting decisions. Representatives may anticipate that responders engage in social comparison and therefore adapt their distribution decisions. In particular, we expect that a strategy of excluding one responder is adopted less often when there is full information about the distribution decision.

Voting can be organized in a secret or public way. In repeated interactions, this difference can be crucial for the voting decisions of responders and in consequence for the distribution decision of the representative. If multiple responders vote publicly, the representative obtains information about the acceptance thresholds of the responders. Income maximizing representatives may use this information

8 Note that this is exactly the same amount as the resources to be distributed. Consequently, keeping all resources but being punished results in a status-quo for the representative. Compared with this benchmark, representatives have a strong incentive to try to avoid punishment by giving more resources to the others, as this could lead to positive net earnings. If they fail to avoid punishment, however, not keeping all resources leads to negative net earnings.

9 In brief, the amount subjects earn with these estimates depends on the reported likelihood estimates and the actual voting decisions of the other members. The additional earnings for a responder are equal to $3+6 p_{j}-3\left(\left(p_{0}\right)^{2}+\left(p_{1}\right)^{2}+\left(p_{2}\right)^{2}\right)$ if $\mathrm{j}$ responders vote in favor of punishment $($ with $\mathrm{j}=0,1,2) \cdot \mathrm{p}_{\mathrm{j}}=\mathrm{P}_{\mathrm{j}} / 100$, with the reported percentages $P_{j}$ representing the percentage that $j$ responders vote in favor of punishment. The additional earnings for the representative are $\sum_{i}^{3}\left[1+2 \mathrm{p}_{j}-\left(\left(p_{\text {yes }}\right)^{2}+\left(p_{n o}\right)^{2}\right)\right]$, with $\mathrm{p}_{\mathrm{j}}=\mathrm{P}_{\mathrm{j}} / 100$. The reported percentages $P_{j}(j=$ yes, no) represent the probability that a specific responder votes in favor of punishment. Consequently, both the representative and the responders can earn an additional earning of maximum 6 'francs' in case their likelihood estimates are completely correct. The participants got to see the formulas in the instructions, but they were told that it was not important to understand them exactly and it was sufficient that they realized that their expected earnings were maximized if they indicated their true likelihood estimates.

10 Although aid programs transfer distributive decision power to local representatives, they do not completely give up their agency. As providers of the aid resources, they are able to influence some rules of the game, related to information access on the distribution of the resources and on the use of the political control institution by the community members. 
to shift resources away from those agents that are more difficult to satisfy. Such an exclusion-strategy allows them to increase their personal share while remaining unpunished. Responders who disagree with the current distribution may anticipate this and, therefore, refrain from voting in favor of punishment. We, therefore, expect relatively less punishment and higher earnings for representatives when voting is public in comparison to when it is secret.

In total we organized four different treatments (Table 1) combining private and common information about the representative's distribution decision with secret and public voting about punishment.

Table 1. Treatments and number of groups

\begin{tabular}{lcc}
\hline & Secret voting & Public voting \\
\hline Private information on the distribution & 8 groups & 8 groups \\
Common information on the distribution & 7 groups & 8 groups \\
\hline
\end{tabular}

The experiment was completely computerized using Z-tree software (Fischbacher, 2007) and conducted in the computer lab of Maastricht University in the second half of 2006. In total 124 students participated in 31 groups. $52.4 \%$ of the participants were male and average age was 21.8 with a minimum of 18 and maximum of 31 . None of the students had participated in a similar experiment before. Each session took between 90 and 120 minutes, and average earnings were Euro 22.20, with the highest earnings being Euro 31.70 and lowest Euro 10.70. Detailed experimental procedures and the instructions can be found in Appendix 1.

\section{Empirical results}

In this section, we look at the representatives' distribution decisions and the responders' voting decisions, and how they interact with each other and with the different information conditions. We first examine the determinants of the responders' voting decisions, followed by the strategies of the representatives.

\subsection{Responders' voting behavior}

An obvious candidate for explaining voting behavior is the received money share from the representative. However, to account for possible social comparisons and emotional factors we do not use the money share itself as an explanatory variable but the expressed satisfaction with the received share. ${ }^{11}$ In each round, after information about the received share is revealed, responders are asked

11 The satisfaction about the received share is highly correlated with the received share (model not shown). The satisfaction about the received share, however, also depends on other variables, such as emotional elements like anger or happiness, and the relative comparison with other group members when information on the 
about their satisfaction level with their share (9 point scale with range $[-4,4])$. We expect that lower satisfaction is correlated with a higher likelihood for voting for punishment.

We also expect a treatment effect for voting being public or secret. When voting is public, representatives know the voting behavior and may retaliate against 'protesting' responders when making new distribution decisions in subsequent rounds. If responders anticipate such behavior, they may be reluctant to vote in favor of punishment if voting is public. Clearly, there might be an interaction effect with the responder's satisfaction. Especially, more dissatisfied responders may care less about the consequences of their voting decision on future earnings for at least two reasons. First, negative emotional factors may outweigh earnings related considerations, and second, responders with a low share have not much to lose anymore.

From public goods experiments it is well known that many people act as conditional cooperators (Fischbacher et al., 2001; Fischbacher and Gächter, 2006). Hence, if punishment is considered a public good, responders may cast a vote in favor of punishment only if they expect the other responders to do the same. To control for such a conditional voter effect, we add the responder's likelihood estimates that exactly one and exactly two other responders vote in favor of punishment. In addition, we control for the information condition on the distribution decisions and the sex and the endowment of the responder.

Table 2 shows the results of a probit regression where the dependent variable takes the value 1 if a responder voted for punishment and zero otherwise. In all regressions, standard errors are corrected for intra-group dependencies. The results show that the dissatisfaction with the received share exerts a significant positive influence on a responder's likelihood to vote in favor of punishment. As hypothesized, when voting is public, responders are significantly more reluctant to vote in favor of punishment; a tendency that is mitigated with lower satisfaction levels as indicated by the significant interaction effect (Satisfaction $\mathrm{x}$ public voting).

Responders are clearly conditional voters for punishment. The likelihood to vote in favor of punishment increases significantly when responders believe that both other responders also vote for punishment but is insignificant if they believe that only one other will do so. The insignificant interaction terms between expectations and public voting show that this result does not differ between private and public voting.

Interestingly, female responders have a much lower likelihood of voting in favor of punishment in comparison with male responders. A similar effect exists for middle-endowment players. The information on the distribution decision has a marginally significant effect; responders tend to vote for

distribution decisions is commonly known. For this reason, we include it as explanatory variable instead of the received share. 
punishment with a higher likelihood if the distribution decision is commonly known. ${ }^{12}$ We summarize our findings on the responders' likelihood to vote in favor of punishment in a first result.

Table 2. Voting decision-making (probit)

Dependent variable: probability to vote in favor of punishment

\begin{tabular}{lrl} 
& Marg. prob. & S.E. \\
\hline Satisfaction with own share & -0.097 & $0.017^{* * *}$ \\
Public voting (dummy) & -0.200 & $0.114^{*}$ \\
Satisfaction x public voting & -0.041 & $0.019^{* *}$ \\
Expectation 1 other vote & 0.114 & 0.128 \\
Expectation 2 other votes & 0.441 & $0.135^{* * *}$ \\
Public voting x expectation 1 other vote & 0.221 & 0.158 \\
Public voting x expectation 2 other votes & -0.031 & 0.163 \\
Female responder (dummy) & -0.147 & $0.059^{* *}$ \\
Middle-endowment responder (dummy) & -0.136 & $0.053^{* *}$ \\
Common information (dummy) & 0.117 & $0.060^{*}$ \\
Round & 0.002 & 0.008 \\
\hline N & 930 & \\
Pseudo R-squared & 0.4083 & \\
Wald chi2(12) & 254.90 & \\
Prob > chi2 & 0.0000 & \\
Observed probability & 0.4527 & \\
\hline
\end{tabular}

Notes. Probit regression with robust standard errors to correct for intra-group dependencies. Significance levels (two-sided): $*=10 \%, * *=5 \%, * * *=1 \%$.

\section{Result 1. Determinants of responders' voting decisions}

A responder's propensity to vote in favor of punishment significantly increases with his dissatisfaction about the received share. It also increases with the belief that both other responders will vote in favor of punishment. When voting is secret or information on the distribution is common, responders are less reluctant to vote in favor of punishment. Female and middle-endowment responders have a significantly lower propensity to vote in favor of punishment.

12 More detailed investigation (models not shown) reveals that the gender and endowment differences are mainly driven by differences in voting behavior when the information on the distribution decision is private. 


\subsection{Representatives' distribution decision}

Here we present the representatives' distribution decision when the high-endowment player is the representative, i.e. the first 10 rounds of the experiment. We start with some descriptive statistics on the representatives' distribution decisions followed by more detailed analysis.

Table 3 shows that on average representatives only give around $50 \%$ to the three responders in total although their endowment is already 50\% higher than the middle-endowment players' endowments, and even 100\% higher than the low-endowment players' endowments. This suggests a strong tendency towards earnings maximization and a considerable ineffectiveness of the punishment by voting institution.

Table 3. Descriptive statistics of distributive decisions

\begin{tabular}{lcccc}
\hline & & \multicolumn{2}{c}{ Mean share of ... } & \\
Treatments: & High-endow & Middle-endow & Middle-endow & Low-endow \\
player & player 1 & player 2 & player \\
\hline \multirow{2}{*}{ Sec.vot./pr.info } & 106.88 & 28.68 & 34.13 & 30.33 \\
& $(56.67)^{\text {a }}$ & $(27.00)$ & $(26.06)$ & $(25.06)$ \\
Pub.vot./pr.info & 98.25 & 38.26 & 32.59 & 30.90 \\
& $(46.88)$ & $(21.66)$ & $(25.21)$ & $(28.76)$ \\
Sec.vot./com.info & 102.33 & 29.64 & 35.81 & 32.21 \\
& $(63.60)$ & $(26.02)$ & $(25.65)$ & $(29.50)$ \\
Pub.vot./com.info & 88.49 & 38.59 & 39.96 & 32.96 \\
& $(61.43)$ & $(25.67)$ & $(23.97)$ & $(27.09)$ \\
Total & 98.88 & 33.93 & 35.62 & 31.58 \\
& $(57.71)$ & $(25.57)$ & $(25.38)$ & $(27.61)$ \\
\hline
\end{tabular}

${ }^{\mathrm{a}}$ Standard deviation between parentheses. Group averages over all rounds.

Representatives who want to maximize earnings have not only to consider the share they keep for themselves but also how to avoid punishment, as punishment costs are considerable. Table 4 shows the average punishment frequency after pooling all rounds over all groups by treatment. It shows that overall punishment is quite frequent and that there are considerable differences between treatments. Independent of the information on the distribution decision punishment is more frequent when voting is secret, and for any given voting condition, when information on the distribution is common. ${ }^{13}$ Using group averages across all rounds as units of observation, differences are significant between public voting/private information and secret voting/common information (Mann-Whitney $U=4.50$; one-

13 Note that this is consistent with the regression results in the previous section on the responders' propensity to vote in favor of punishment. 
sided $\mathrm{p}=.002$ ). For all other pair-wise treatment comparisons, differences are not statistically significant (one-sided p-values $>.115$ ).

Table 4. Average punishment frequency by treatment

\begin{tabular}{lcc}
\hline & $\begin{array}{c}\text { Private } \\
\text { information }\end{array}$ & $\begin{array}{c}\text { Common } \\
\text { information }\end{array}$ \\
\hline Secret voting & $42.50 \%$ & $60.00 \%$ \\
Public voting & $26.25 \%$ & $42.25 \%$ \\
\hline
\end{tabular}

Based on the observation that punishment rates differ across treatments, we also expect that strategy choices of the representatives differ across treatments, in particular, when comparing public voting/private information and secret voting/common information.

To investigate this we classify the representatives' strategies using the following two dimensions. First, we take into account the share representatives keep for themselves. Since keeping more than 50 'francs' can hardly be considered as fair we distinguish between distributions where the representative keeps more than 50 'francs' from distributions where he keeps less or equal than 50 'francs'. Second, when taking a distribution decision, representatives may consider the number of responders to exclude from the resources, where exclusion means not giving any resources. Combining both considerations gives eight possible classes of strategies. As Table 5 shows, two of these classes are empty and two other very low percentages. We focus, therefore, on the following four classes of strategies.

'Exclude-all': This strategy consists of keeping the entire pie and, thus, excluding all responders from the resources. This strategy is followed in $17.74 \%$ of the cases. 'Exclude-one': This strategy consists of excluding exactly one responder and is with $32.90 \%$ of all cases the most commonly chosen strategy. Note that excluding exactly one responder is in almost all of the cases combined with the representative keeping shares higher than 50 'francs'. The 'no-exclusion-low-share'-strategy and the 'no-exclusion-high-share'-strategy have in common that they do not exclude any of the responders. They differ in that in the former the representative keeps less (or equal) than 50 while in the latter he keeps more than 50. 'No-exclusion-low-share' contains the case where the representative does not keep any resources (3.23\% of the cases) and the case where he distributes the resources equally among all players $\left(12.8 \%\right.$ of the cases). ${ }^{14}$

Figure 2 shows the relative frequencies of each strategy in each treatment. Across treatments, there are considerable differences in the use of the different strategies. In particular, with private information on the distribution decision the 'exclude-one' strategy seems very popular whereas when it is combined with public voting the 'exclude-all' strategy seems very unpopular.

${ }^{14}$ It is worthwhile to note that a strategy of excluding two responders is almost never followed $(0.65 \%$ of all cases). From the perspective of the representative, this makes sense, because to avoid punishment a representative needs at least two responders satisfied with their received share. 
Table 5. Classification of strategies

\begin{tabular}{llll}
\hline & & \multicolumn{2}{c}{ Share of representative } \\
& & $\leq 50$ & $>50$ \\
\hline \multirow{3}{*}{ Excluded responders } & 0 & $26.13 \%$ & $19.68 \%$ \\
& 1 & $2.90 \%$ & $32.90 \%$ \\
& 2 & $0.00 \%$ & $0.65 \%$ \\
& 3 & $0.00 \%$ & $17.74 \%$ \\
\hline
\end{tabular}

Note: $\mathrm{N}=1240$. Pooled over all rounds, groups and treatments

A Mann-Whitney test, using the relative frequency of each strategy over all rounds for each group as unit of observation, reveals that with private information the 'exclude-all' strategy is significantly less often used with public voting than with secret voting (Mann-Whitney $U=18.50$; one-sided $p=$ .080). It is also revealed that this strategy is significantly less often used in public voting/private information than in secret voting/common information (Mann-Whitney $U=13.00$; one-sided $p=$ .047). Here again the difference can be attributed to the voting condition. For the pooled data the relative frequency of this strategy is significantly lower with public voting than with secret voting (Mann-Whitney $U=77.00$; one-sided $p=.047$ ) but not when comparing private information and common information (Mann-Whitney $\mathrm{U}=107.00$; one-sided $\mathrm{p}=.273$ ). For all other pair-wise treatment comparisons, differences are not statistically significant (one-sided p-values $>.150$ ).

Figure 2. Representatives' strategy choice by treatment

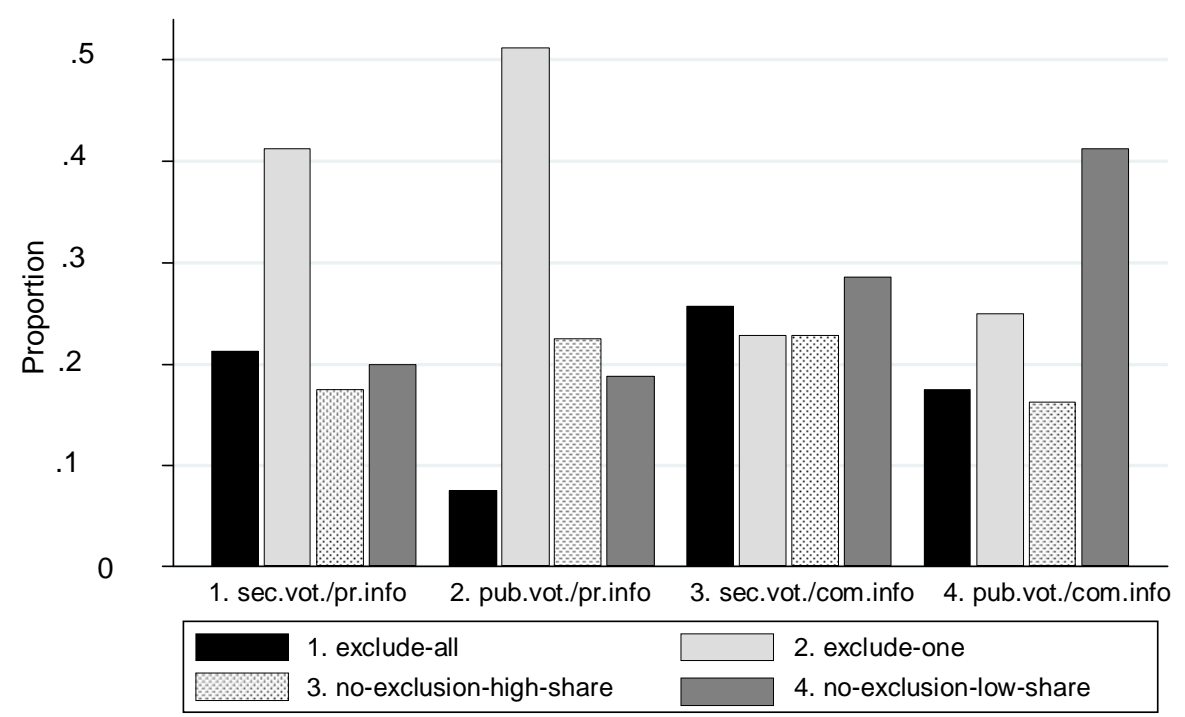

Note. All rounds and groups pooled.

The 'exclude-one'-strategy is significantly more often used in public voting/private information than in secret voting/common information (Mann-Whitney $U=11.50$; one-sided $p=.027$ ) and in public 
voting/common information (Mann-Whitney $\mathrm{U}=13.50$; one-sided $\mathrm{p}=.025) .{ }^{15}$ These differences are the result of the information regarding the distribution decision. Using the pooled data, if there is common information on the representative's decision 'exclude-one' is used significantly less often than when this information is private (Mann-Whitney $U=70.00$; one-sided $p=.025$ ). No such difference is found when comparing secret and private voting (Mann-Whitney $\mathrm{U}=102.00$; one-sided $\mathrm{p}=.248$ ). Finally, the relative frequencies of the 'no-exclusion-low-share'-strategy and the 'noexclusion-high-share'-strategy do not show any significant difference when compared between treatments.

As there are middle-endowment and low-endowment responders, an important question relates to which responders are more likely to be excluded when the representative follows the 'exclude-one'strategy. To see this, we estimated a probit regression (with standard errors corrected for intra-group dependencies) where we only consider observations with 'exclude-one'-strategies and control for the endowment of the responder. Pooling both secret voting treatments, the estimated coefficient is not statistically significant from zero (one-sided $\mathrm{p}=.390 ; \mathrm{N}=126$ ). With public voting, however, lowendowment responders have a $40 \%$ higher probability to be excluded (one-sided $\mathrm{p}=.004 ; \mathrm{N}=180$ ). Note, that this result is perfectly consistent with our analysis on the voting decisions of the responders, where we found that low-endowment responders have a higher propensity to vote in favor of punishment than middle-endowment responders. With public voting, representatives obtain information on individual voting decisions and are able to make inferences about the responders' propensity to vote in favor of punishment. Observing that low-endowment responders have a higher propensity to vote in favor of punishment, representatives may be more inclined to exclude lowendowment responders than middle-endowment responders. The second result summarizes the observations regarding the representative's strategy choices.

\section{Result 2. Representatives' strategy choices}

With public voting the relative frequency of the 'exclude-all'-strategy is significantly lower than with secret voting. With private information on the distribution decision and public voting the relative frequency of the 'exclude-one'-strategy is highest. Moreover, when the representative follows the 'exclude-one' strategy, the low-endowment responder has a $40 \%$ higher probability of being excluded if voting is public.

Up to now, we have ignored any potential dynamics in choices. Since a representative's strategy choice may change with punishment experience, we shall have a closer look to this dynamics. Potentially important factors behind the dynamics of the representative's strategy choice are his

15 No other pair-wise treatment comparisons show statistically significant differences (one-sided p-values > $.190)$. 
experiences and expectations about punishment. Being punished may change a representative's expectations and with it his strategy choice.

Table 6 shows for each treatment and strategy the Spearman rank-order correlation coefficient between the relative frequency of the strategy (pooled across all groups in a treatment) and the round number. The figures in the first column show that the frequency of the 'exclude-all'-strategy strongly and significantly increases over in all but the public voting/private information treatment.

In the secret voting/private information treatment, this increase is combined with a significant decrease of the 'exclude-one'-strategy. When information on the distribution is common, the increase in the use of 'exclude-all' is at the expense of the 'no-exclusion-high-share'-strategy.

Table 6. Correlations between use of strategies and time

\begin{tabular}{lccccc}
\hline \multirow{2}{*}{ Treatments } & \multicolumn{5}{c}{ Strategies } \\
& exclude-all & exclude-one & $\begin{array}{c}\text { no-exclusion } \\
\text { high-share }\end{array}$ & $\begin{array}{c}\text { no-exclusion } \\
\text { low-share }\end{array}$ & \% punishment \\
\hline Sec.vot./pr.info & 0.833 & -0.634 & -0.463 & 0.439 & 0.514 \\
& $(.003)$ & $(.049)$ & $(.178)$ & $(.205)$ & $(.128)$ \\
Pub.vot./pr.info & -0.275 & 0.303 & 0.120 & -0.199 & -0.222 \\
& $(.441)$ & $(.396)$ & $(.742)$ & $(.581)$ & $(.538)$ \\
Sec.vot./com.info & 0.749 & 0.342 & -0.619 & 0.178 & -0.044 \\
& $(.013)$ & $(.334)$ & $(.056)$ & $(.624)$ & $(.903)$ \\
Pub.vot./com.info & 0.818 & 0.199 & -0.824 & 0.386 & 0.161 \\
& $(.004)$ & $(.582)$ & $(.003)$ & $(.270)$ & $(.657)$ \\
\hline
\end{tabular}

Notes. All groups pooled. Two-sided p-values between parentheses.

In those treatments where the frequency of the 'exclude-all'-strategy increases with time, punishment rates are also considerable (recall Table 4). One might expect that the increasing use of the 'excludeall'-strategy leads to this high punishment frequencies. However, as confirmed by the insignificant Spearman correlation coefficients in the last column of Table 6, punishment rates do not significantly increase over time and, thus, have been high right from the start. This suggests that it is rather failure in avoiding punishment that induces representatives to switch to the 'exclude-all'-strategy. This is confirmed by a probit regression estimating the likelihood that a representative changes his strategy into the 'exclude-all'-strategy after being punished in the previous round (only considering the rounds where the strategy in the previous round was not the 'exclude-all' strategy). The estimation shows that representatives have a 33\% higher likelihood of changing their strategy into the 'exclude-all'-strategy if they were punished in the previous round than if they were not punished (two-sided $\mathrm{p}<.001 ; \mathrm{N}=$ 222; robust standard errors correcting for intra-group dependencies). 
There are two potentially contrary motivations that may trigger representatives to switch to the 'exclude-all' strategy. First, it my be mere revenge for being punished in the sense of a tit-for-tat strategy, but second, it may also be because the representative expects higher earnings with an 'exclude-all' strategy, especially if other strategies do not avoid punishment. More generally, we can look at the expected earnings for the different strategies. Recall that we asked the representative for the likelihood that any specific responder votes in favor of punishment. With this information and the actual distribution decisions, we can calculate the expected earnings for each strategy.

\section{Figure 3. Expected earnings of the representative by strategy (rounds 1-10)}

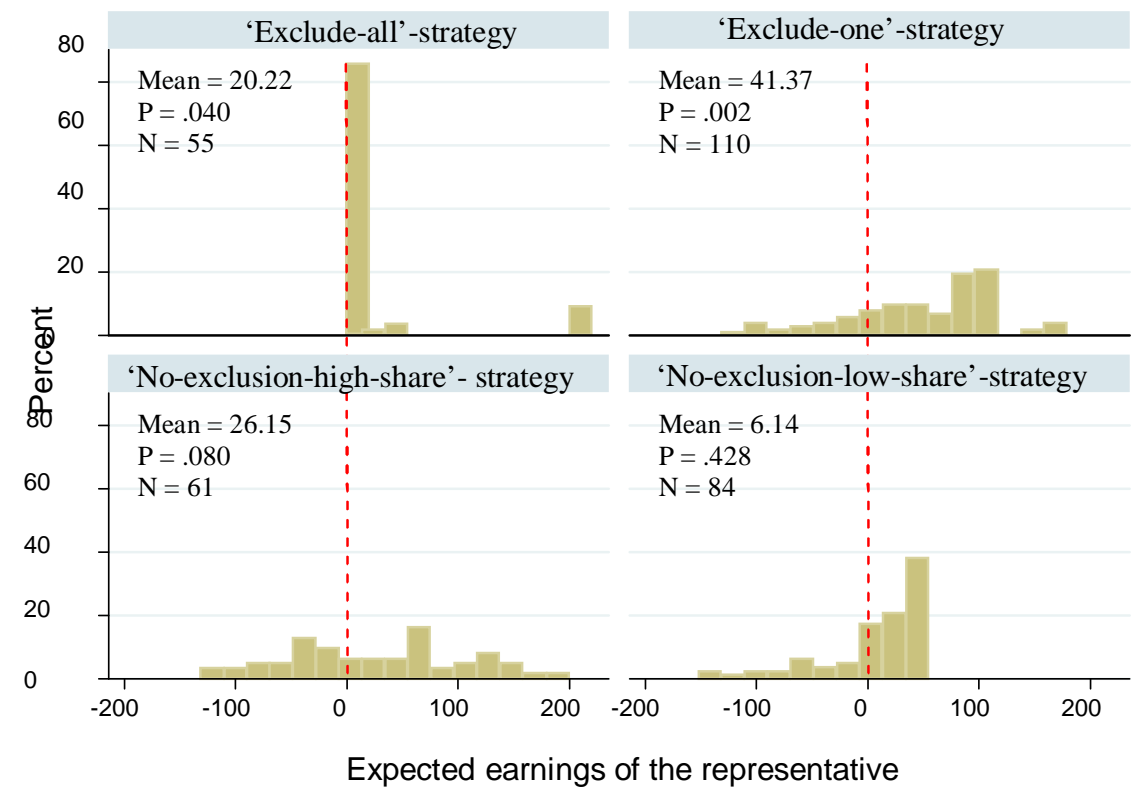

Notes. All rounds and treatments pooled. Two-sided p-values are calculated by estimating an OLS regression with only a constant term and applying robust standard errors to correct for intra-group correlations

Figure 3 shows the distribution of the expected earnings by strategy. We observe that when the representative chooses the 'exclude-all'-strategy, in more than $80 \%$ of the cases the expected earnings are zero, implying that the representative expected to be punished. On the other hand, however, there is a non-negligible fraction of cases where punishment is not expected and, hence, expected earnings are rather high. In conclusion, the 'exclude-all' strategy is mainly used as a non-earnings maximizing revenge option, but not exclusively so. The 'exclude-one' strategy completely excludes one responder making it hardly justifiable on fairness grounds. At the same time, it produces the highest expected earnings suggesting that this strategy is mainly used for earnings maximizing reasons. Responders who play the 'no-exclusion-high-share' strategy also expect positive earnings. Only the 'no-exclusionlow-share'-strategy does not lead to positive expected earnings.

The presented evidence suggests that on average representatives choose their strategies with an earnings motive in mind. Figure 4 shows the distribution of the difference between representative's expected earnings in the current round and their earnings in the previous round and distinguishes 
between strategy choices that are different from those in the previous round and strategy choices that are the same as in the previous round. It shows that when representatives do not change their strategy they expect to obtain similar earnings as in the previous round. However, when they change their strategy they clearly expect to receive significantly higher earnings than they obtained with the strategy in the previous round. This gives support to the hypothesis that at least those representatives who change their strategy do this for earnings reasons and take their expectations on the responders' voting decisions into account.

Figure 4. Expected earnings round $t$ - earnings round t-1 (rounds 1-10)

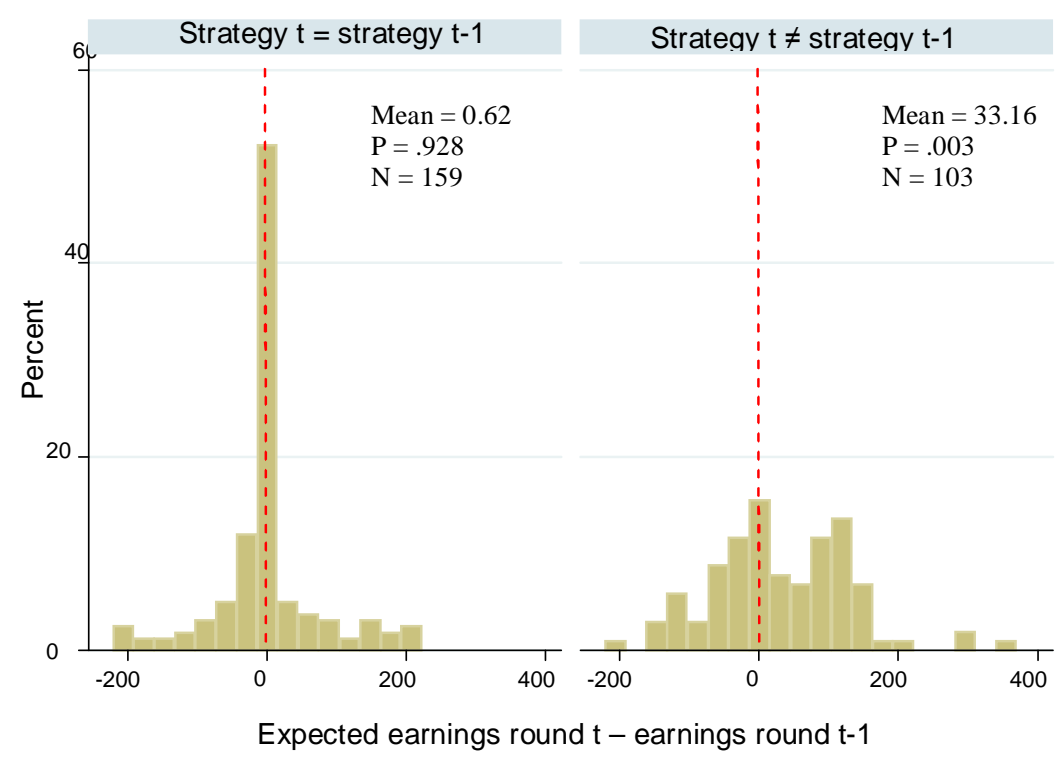

Notes. All rounds and treatments pooled. Two-sided p-values were calculated by estimating an OLS regression with only a constant term and applying robust standard errors to correct for intra-group correlations

It is interesting to note, that in the public voting/private information treatment the 'exclude-one'strategy makes up more than a half of all strategy choices. In this treatment we also do not see any significant trend in strategy revisions (see Table 6), which is consistent with the low punishment rates It seems that receiving information on the responders' voting behavior enables representatives to infer about the responders' acceptance thresholds, which helps to avoid punishment, and to successfully apply the 'exclude-one'-strategy. We summarize the above discussion in a third result. 


\section{Result 3. Strategy choice and strategy revision}

Being punished induces representatives to switch to the 'exclude-all'-strategy. Most representatives seem to use it for revenge reasons because it mostly produces zero expected earnings. However, most do not persist in using this strategy and switch to the strategies 'exclude-one' and 'noexclusion-high-share' which are expected to be more profitable.

In the public voting/private information treatment where punishment is relatively infrequent, many representatives follow the 'exclude-one'-strategy without exhibiting a significant trend to change strategies.

\subsection{Political change}

In a last section, we briefly discuss the effect of a political change where the role of the representative is taken from the high-endowment player and given to the low-endowment player, while keeping the group composition constant.

Figures $5 \mathrm{a}$ and $5 \mathrm{~b}$ show the mean final earnings (inclusive endowments and after deduction of punishment costs) of each player type over all groups by treatment. They also show the distribution of the endowments. Comparing the distribution of the final earnings with the distribution of the endowment allows us to detect whether the distribution of the additional resources makes the final distribution more equal. The results are mixed when the high-endowment player is the representative, but the final distributions are clearly more equal than the distribution of the endowments when the low-endowment player acts as representative.

To test whether the distributions of the final earnings in the second part are more equal than in the first part, we calculate the standard deviations in final average earnings across players in each group and compare them between the first and the second part of the experiment for each treatment. A Wilcoxon signed ranks test shows that the standard deviations are significantly different in the public voting/private information treatment $(\mathrm{Z}=-2.380$; two-sided $\mathrm{p}=.017)$ and the public voting/common information treatment $(\mathrm{Z}=-2.380$; two-sided $\mathrm{p}=.017)$, but not in any of the secret voting treatments $(\mathrm{Z}>-1.540$; two-sided $\mathrm{p}>$.123).

In all treatments, in most of the cases, the low-endowment representative keeps a very high share of the resources. In $99.68 \%$ of the decisions the representative keeps at least 50 'francs', in $73.87 \%$ even at least 100 'francs' of the 200 'francs'. The low-endowment representatives also make very frequent use of the 'exclude-one'-strategy. In the treatments with private information on the distribution, it is implemented in $82.5 \%$ and $72.5 \%$ of all cases, when voting is secret and public, respectively. If the information about the distribution decision is common these percentages are lower but still reach $50.0 \%$ and $58.8 \%$ when voting is secret and public, respectively. In most of the cases where this strategy is used it is the 
high-endowment player who is excluded. The frequencies are similar across treatments and range from $47.5 \%$ in private information/secret voting to $52.5 \%$ in private information/public voting. A relatively large proportion (30.0\% over all treatments) of these exclusion-decisions is the result of a 0-50-50-100 proposal, which equalizes the final earnings. Other strategies are much less frequent. In only $9.68 \%$ of the decisions, exactly one of the middle-endowment players is excluded and in only $6.77 \%$ of the decisions, the representative keeps everything.

Figure 5. Distribution of the final earnings by treatment

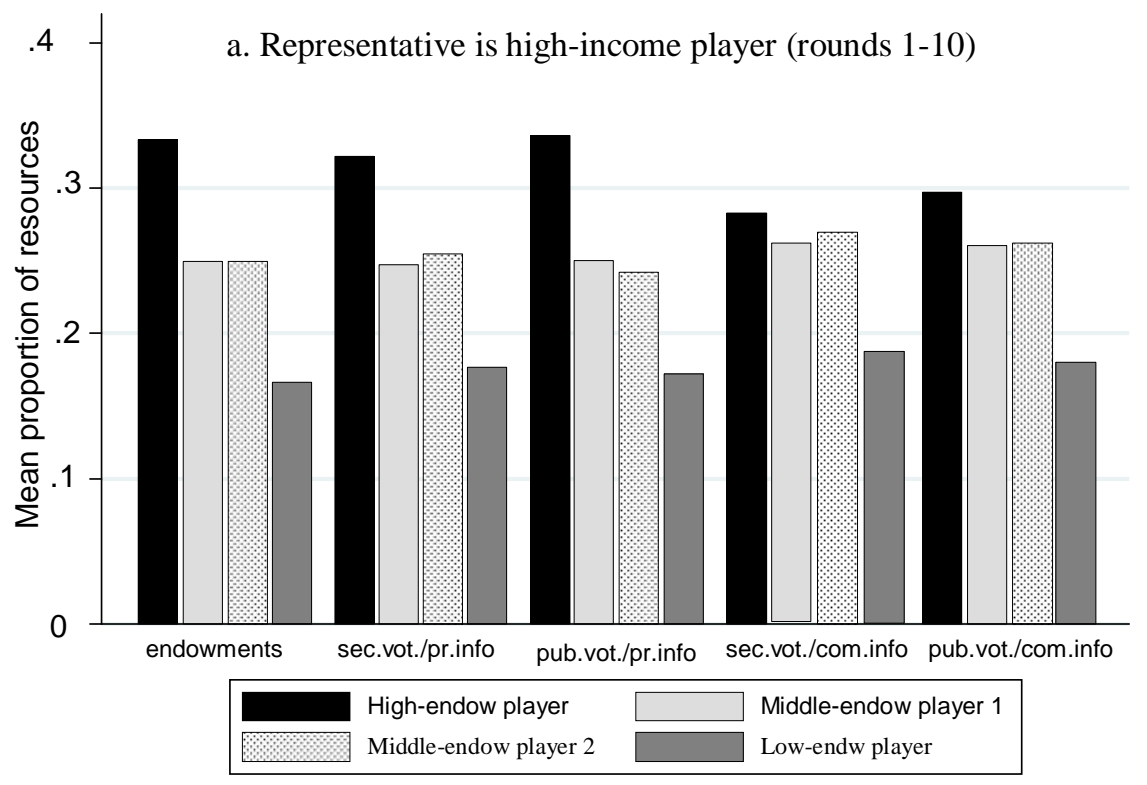

Note. Mean proportions are calculated over all rounds

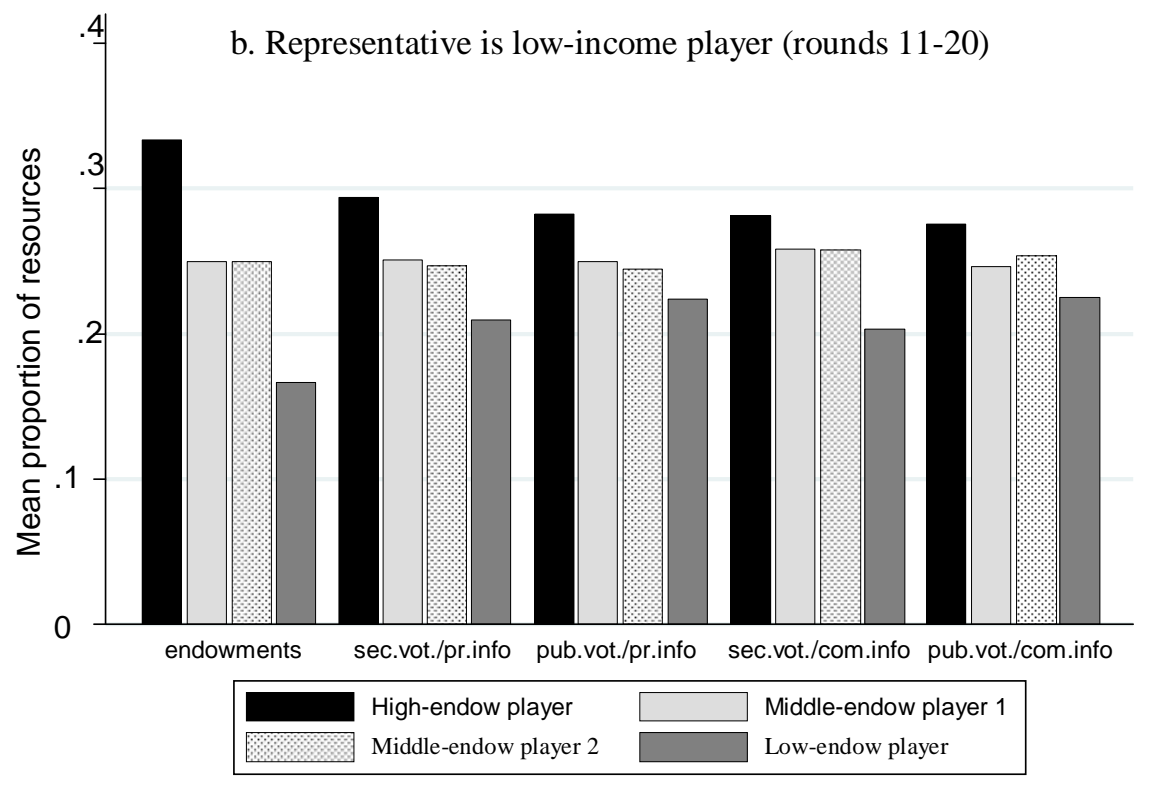

Note. Mean proportions are calculated over all rounds 
Punishment rates vary between 20\%-27\% across treatments and are, hence, substantially and significantly lower than when the high-endowment player is the representative (Wilcoxon signed ranks test, $\mathrm{Z}=-3.038$; two-sided $\mathrm{p}=.002$ ). We attribute this to the fact that, in contrast with the highendowment player as representative, the earnings motive and fairness ideas are aligned making it more acceptable to the responders that the low endowment player keeps more of the resources.

Thus, political change in favor of the poorest player is not only beneficial in distributional terms. It also increases efficiency, measured as the sum of all incomes after punishment over the sum of all incomes before punishment. As punishment costs are constant irrespective of the distribution, there is a direct inverse relation between punishment rates and efficiency. Consequently, as punishment rates are considerably lower when the low-endowment player becomes the permanent representative, efficiency is considerably higher.

\section{Result 4. Effects of political change}

With the low-endowment player as the permanent representative, punishment rates are substantially lower and, thus, efficiency substantially higher. In most of the cases, the representative keeps equal or more than half of the pie. The 'exclude-one'-strategy becomes more common and when it is followed in most of the cases, it is the high-endowment player who is excluded. With public voting, the final distribution of the net earnings becomes more equal.

\section{Discussion and policy implications}

In this study, we experimentally examine the influence of local information conditions on elite capture and social exclusion in community-based development schemes. Not only information on the distribution of aid resources through these schemes, but also information on who makes use of an available punishment mechanism through majority voting may be important. In our laboratory experiment, a permanent representative, being the richest of an economically heterogeneous group, is asked to distribute a fixed amount of resources among the group members in subsequent rounds. After each distribution decision, the other members have the ability to punish the representative, but only if a majority of them votes in favor of doing so.

The main results are the following. First, many representatives try to satisfy a political majority who would then abstain from using the punishment mechanism, while they exclude those community members whose approval is then not required. The frequency of this exclusion strategy is highest with private information on the distribution and public voting. Second, when voting is public, responders are more reluctant to make use of the punishment mechanism, and representatives exclude poorer responders more often. Third, punishment is largely ineffective as, instead of enforcing representatives to reduce their share, it actually induces them to try to capture all economic resources. Fourth, if a 
poor agent takes the representative's role, punishment rates drop and final distributions become substantially more equal.

Other results are that a responder's likelihood of voting in favor of punishment increases with his dissatisfaction with the received share. At the same time, responders take into account what they expect other responders would do. In particular, there is strong evidence in favor of conditional voting in the sense that a responder's propensity to vote in favor of punishment strongly increases only if all other responders are expected to do so as well.

Before discussing some policy implications of our study, an important methodological note is required on the benefits of laboratory experiments for development economics. A big advantage of conducting experiments in the laboratory is that it allows for gathering data that is otherwise hard to get. For instance, for our purpose, it was important to receive information about people's beliefs and opinions and behavior in different controlled environments regarding the information people have about distribution decisions and voting behavior. For robustness reasons it was also necessary that the same situations could be replicated. All this is fairly impossible to achieve in the field but necessary if one wants to get reliable data for different policy options. Potential caveats, however, exist regarding the external validity of experiments conducted in laboratories. In particular, the behavior of the population in the lab, mostly consisting of university students, may not be representative for the population of interest. Regarding experiments exhibiting some proximity to our experiment the evidence is mixed, however. For instance, Fehr and List (2004) report that CEO's trust more and are more trustworthy than students. List (2004) and, Egas and Riedl (2008), on the other hand, find little differences in social behavior between students and non-students, but both also report a positive correlation between age and pro-social behavior. To make statements about external validity of laboratory experiments, additional information can be included into the analysis. This can be done through statistical tests (on this see Harisson and List, 2004: 1018-19), through sound field studies (Ostrom, 1998: 17), or by comparing the results of experimental studies across different settings.

Following the latter approach, the field experiments of Henrich et al. (2004) are particularly useful to make validity judgments about our setting. Henrich et al. conducted ultimatum game experiments in 15 different small-scale societies in the South. An important result is that behavior in these small-scale societies does not differ qualitatively, but it does so in a quantitative way. The ultimatum game offers increase with two important characteristics of small-scale societies: the 'Payoff to Cooperation' and a 'Market Integration' index. Comparing ultimatum game offers made by northern students in computer laboratories with those made in small-scale societies in the South (Cardenas and Carpenter, 2008), it can be observed that the former are most similar to small-scale societies with considerable market integration. We are therefore confident that the results of our laboratory experiment, which - as discussed before - shows some resemblance to the ultimatum game, are particularly valid for these types of societies. 
With these caveats in mind, we highlight some policy implications for community-based development suggested by our study. Assuming that policymakers have a certain margin to influence institutions of information provision and political voice and control, our results indicate that they need to choose between the lesser of two evils. With private information and public voting, punishment rates are substantially lower and thus efficiency higher. At the same time, however, it is highly probable that one responder (often the poorest) is excluded from all resources. Our evidence also indicates that more important than these information conditions is the selection of the representative. Making the poorest player the permanent representative not only makes the distribution of the final earnings more equal, it also leads to less punishment and fewer wasted resources. Such a political change is thus beneficial in both distributional and efficiency terms. This suggests that donors should try to make such a political change feasible. 


\section{References}

Abbink, K., Ellman, M. 2005. The Donor Problem, mimeo.

Abraham, A., Platteau, J.P., 2004. Participatory Development: When Culture Creeps. In: V. Rao and M. Walton, eds., Culture and Public Action: A Cross-Disciplinary Dialogue on Development Policy. Palo Alto, Calif.: Stanford University Press.

Alderman, H., 2001. Do local officials know something we don't? Decentralization of targeted transfers in Albania. Journal of Public Economics 83 (3), 375-404.

Bierschenk, T., Chauveau, J.-P., Olivier De Sardan, J.-P., 2000. Courtiers en développement; les villages africains en quête de projets. Paris: Karthala.

Bolton, G., Ockenfels, A., 2000. 'ERC - A Theory of Equity, Reciprocity and Competition'. American Economic Review 90, 166-93.

Camerer, C., Thaler, R., 1995. Anomalies: Ultimatums, Dictators and Manners. Journal of Economic Perspectives 9 (2), 209-219.

Cardenas, J.C., 2003. Real wealth and experimental cooperation: experiments in the field lab. Journal of Development Economics 70 (2), 263-289.

Cardenas J.C., Carpenter, J., 2008. Behavioral Development Economics: Lessons from field labs in the developing world. Journal of Development Studies 44 (3), 337-364.

Cason, T., Khan, F., 1999. A laboratory study of voluntary public goods provision with imperfect monitoring and communication. Journal of Development Economics 58, 533-552.

Conning, J., Kevane, M., 2002. Community-based targeting mechanisms for social safety nets: a critical review. World Development 30 (3), 375-394.

Dufwenberg, M., Kirchsteiger, G., 2004. A Theory of Sequential Reciprocity. Games and Economic Behavior 47, 268-298.

Egas, M., Riedl, A. 2008. Altruistic Punishment and the Maintenance of Cooperation. Proceedings of the Royal Society B 275, 871-878.

Falk, A., Fischbacher, U., 2006. A theory of reciprocity. Games and Economic Behavior 54, 293-315.

Fehr, E., List, J. A., 2004. The Hidden Costs and Returns of Incentives - Trust and Trustworthiness among CEOs. Journal of the European Economics Association 2, 743-771.

Fehr, E., Schmidt, K.M., 1999. A Theory of Fairness, Competition and Cooperation. Quarterly Journal of Economics 114 (3), 817-68.

Fischbacher U., Gächter, S. Fehr, E., 2001. Are People Conditionally Cooperative? Evidence from a Public Goods Experiment. Economic Letters 71, 397- 404.

Fischbacher U., Gächter, S., 2006. Heterogeneous social preferences and the dynamics of free riding in public goods, IEW Working Paper No. 261, University of Zurich 2006 
Fischbacher, U., 2007. z-Tree: Zürich toolbox for ready-made economic experiments. Experimental Economics 10 (2), 171-178.

Galasso, E., Ravallion, M., 2001. Decentralised targeting of an anti-poverty program, the World Bank Development Research Group.

Güth W., Schmittberger, R., Schwarze, B., 1982. An experimental analysis of ultimatum bargaining. Journal of Economic Behavior and Organization 3, 367-388.

Harrison, G., List, J., 2004. Field Experiments. Journal of Economic Literature 42 (4), 1009-1055.

Henrich, J., Boyd, R., Bowles, S., Camerer, C., Fehr, E., Gintis, H., 2004. Foundations of Human Sociality: Economic Experiments and Ethnographic Evidence from Fifteen Small-Scale Societies. Oxford University Press.

Hoffman E., McCabe, K., Shachat, K., Smith, V., 1994. Preferences, Property Rights, and Anonymity in Bargaining Games. Games and Economic Behavior 7 (3), 346-380.

Karlan, D., 2005. Using Experimental Economics to Measure Social Capital and Predict Real Financial Decisions. American Economic Review 95 (5), 1688-1699

Knez, M.J. and Camerer, C.F., 1995. Outside options and social comparison in three-player ultimatum game experiments. Games and Economic Behavior 10, 65-94.

List, J. A. 2004. Young, Selfish and Male: Field Evidence of Social Preferences. The Economic Journal 114, 121-149.

Mansuri, G., Rao, V., 2004. Community-based and -driven development: a critical review. The World Bank Research Observer 19 (1), 1-39

Offerman, T., 1997. Beliefs and Decision Rules in Public Good Games: Theory and Experiments. Kluwer, Dordrecht/Boston/London.

Ostrom, E., 1998. A Behavioral Approach to the Rational Choice Theory of Collective Action: Presidential Address. The American Political Science Review 92 (1), 1-22.

Platteau, J.P., Abraham, A., 2002. Participatory Development in the Presence of Endogenous Community Imperfections. Journal of Development Studies, 104-136.

Platteau, J.P., Gaspart, F., 2003. The risk of resource misappropriation in community-driven development. World Development 31 (10), 1687-1703.

Riedl, A., Vyrastekova, J., 2004. Responder Behavior in Three-Person Ultimatum Game Experiments, mimeo.

Slembeck, T., 1999. Reputations and Fairness in Bargaining Experimental Evidence from a Repeated Ultimatum Game With Fixed Opponents, Discussion Paper No. 9904, Department of Economics - University of St. Gallen, 21p. 


\section{Appendix 1: Experimental procedures and instructions}

\section{Experimental procedures}

Several measures were taken to guarantee anonymity. To exclude the possibility that participants could make inferences about the group to which they belonged each session was organized with at least two groups. Moreover, participants were seated randomly in the computer lab with isolated cubicles. It was explained that computer numbers were used to recognize participants during the experiment and the data analysis afterwards, but could not be linked to the participants' names. In addition, during the experiment no communication was allowed, mobile phones were switched off and no participants could leave the lab. If participants had a question, they were asked to raise their hand so that one of the experimenters could come and answer the question in private.

After reading the instructions, the participants had to go through some control questions. The experiment did not start before all participants had correctly answered these questions. At the end of the experiment, participants were asked to fill in a short questionnaire. After all had completed this questionnaire, they were paid out confidentially in cash.

\section{Instructions}

In this experiment, you can earn money. The experiment consists of three unrelated parts. That is, your earnings in one part are independent from your earnings in other parts. In each part you can earn 'francs'. The 'francs' you earn will be converted to Euro according to the conversion rate 200 francs $=1$ Euro and paid out to you privately and confidentially after the experiment.

During the whole experiment, you are not allowed to communicate with the other participants in any other way than described in these instructions.

\section{Instructions for part 1}

The first part of the experiment consists of 10 rounds.

\section{Before the start :}

You will be randomly assigned to a group of 4 participants. Group compositions do not change throughout the 10 rounds. The composition of your group is anonymous. Each group member receives randomly one of the letters A, B, C or D as 'ID'. Each letter corresponds to the same person during all 10 rounds.

\section{During the experiment :}

At the beginning of each round, you and all other members in your group receive a fixed amount of francs. This is called your 'endowment'. This endowment is not the same for everyone but depends on the letter ID. In each round, member A receives 200 francs, members $B$ and $C$ receive 150 francs each, and member D receives 100 francs. 
In each round, participant A will also receive 200 additional francs at his/her free disposal. Of these additional francs member A can keep as much as he/she wants for him/herself and give as much as he/she wants to each of the other three participants in the group. We call member A a 'type I' participant, whereas we call the other participants 'type II' participants.

After A has made his/her decision about the distribution of the additional 200 francs, each type II participant (members B, C, and D) will get to know his/her own received amount but not what the others received or what $\mathrm{A} \mathrm{kept}^{16}$.

Thereafter, the type II participants (members B, C and D) have to vote whether or not to deduct francs from A's income. In this case, all type II members (also those who voted against deduction !) have to bear costs of 20 francs each. Voting is secret. This means that nobody will get to know anyone's voting decision ${ }^{17}$.

Before taking any decision in a specific round, you can review all information you received in all past rounds.

After having made his/her decision each participant has to indicate his/her estimate about the voting decisions of the other group members. These estimates are not transmitted to other participants but stay private information. More particularly, type II and type I members have to do the following:

\section{Type II members}

After the individual voting decision but before knowing the outcome of the voting, each type II participant (members B, C, and D) has to give his/her estimates about how many of the other two members will vote in favor of deducting 200 francs from A's income. This works as follows: Each type II member has to indicate what the likelihood is that precisely none, precisely one, or precisely two of the other type II members vote in favor of deduction. These estimates have to be indicated in percentages, that is an integer number between 0 and 100 (inclusive). Note that the three numbers have to sum up to 100.

\section{Type I member}

After having made his/her decision but before knowing the outcome of the voting, the type I member (member A) has to indicate his/her estimates about the voting decisions of each of the type II members (B, C, and D). For each type II member (B, C, and D) he/she has to indicate his/her estimate about the likelihood that a particular type II member votes in favor of or against deducting 200 francs from his/her income.

With the likelihood estimates you can earn additional francs. The amount you earn depends on the reported likelihood estimates and the actual voting decisions of the other members. The earnings are calculated by means of a mathematical formula. It is not important that you exactly understand this formula. Those interested in the precise calculation of these additional earnings can find the formula on the sheet with the summary of the instructions. It is sufficient that you realize that your expected earnings are maximized if you indicate your true estimation of the likelihood. If your estimate is completely correct these earnings are 6 francs, if it is completely wrong they are 0 . With these likelihood estimates you can never incur losses.

16 With common information this phrase was replaced by: 'After A has made his/her decision, each type II participant (members B, C, and D) will get to know his/her own received amount, how much A kept, and the amounts received by the other two members.'

17 With public voting, this phrase was replaced by: 'Voting is public. This means that everybody will get to know everyone's voting decision.' 


\section{Instructions for part 2}

You now continue during an additional 10 rounds. Groups remain the same, so you remain with the same participants in your group.

A round in this part is precisely the same as before except that now member D has become the type I participant and member A has become a type II participant. This means that now it is member D who receives 200 additional francs to his/her free disposal in each round. In addition, in each round participants A, B and C will be given the opportunity to vote in favor of deducting francs from the income of participant D.

\section{Appendix 2: An outcome-based fairness model}

In this appendix, we present equilibria of our game using a Fehr-Schmidt utility function (Fehr and Schmidt, 1999). This utility function allows for self-centered fairness and has been shown to lead to more realistic predictions in diverse settings. Preferences are represented by a utility function for player $\mathrm{i}(=1, \ldots, \mathrm{n})$ of the following form:

$$
U_{i}(y)=y_{i}-\alpha_{i} \frac{1}{n-1} \sum_{j} \max \left\{y_{j}-y_{i}, 0\right\}-\beta_{i} \frac{1}{n-1} \sum_{j} \max \left\{y_{i}-y_{j}, 0\right\},
$$

with $\alpha_{i}, \beta_{i}$ being respectively the envy and guilt parameters of player $\mathrm{i}$, which determine the utility loss due to disadvantageous and advantageous inequality aversion respectively. It is assumed that $\beta_{i} \leq \alpha_{i}$ and $0 \leq \beta_{i}<1$. Applying this utility function to our experimental game, we obtain the following results.

\section{Proposition 1}

- Strategy combinations $(y, y, y)$ and $(n, n, n)$, which are equilibria under standard preferences, are still an equilibrium with Fehr-Schmidt preferences.

- Assuming that envy and guilt parameters are the same for all responders ${ }^{18}$, strategy combinations with exactly one responder voting in favor of punishment (which lead to non-punishment), which are an equilibrium with standard preferences, are no longer an equilibrium with Fehr-Schmidt preferences if:

1. for at least two responders $\mathrm{i}=\mathrm{B}, \mathrm{C}$ and $\mathrm{D}: y_{i} \leq y_{A}$ and $y_{i}-k \leq y_{A}-K ; \alpha \geq 3 \frac{k}{K-k}$

2. for exactly one responder $\mathrm{i}=\mathrm{B}, \mathrm{C}$ and $\mathrm{D}: y_{i} \leq y_{A}$ and $y_{i}-k \leq y_{A}-K$

i) $\alpha \geq 3 \frac{k}{K-k}$; for at least one of both other responders: $\left(y_{i} \leq y_{A}\right.$ and $\left.y_{i}-k \geq y_{A}-K\right)$ and $\left(y_{i} \leq y_{A}-\lambda\right)$, with $\lambda=\frac{3 \mathrm{k}+\beta[K-k]}{(\alpha+\beta)}$

ii) $\quad \alpha<3 \frac{k}{K-k}$; for both other responders: $\left(y_{i} \leq y_{A}\right.$ and $\left.y_{i}-k \geq y_{A}-K\right)$ and $\left(y_{i} \leq y_{A}-\lambda\right)$, with $\lambda=\frac{3 \mathrm{k}+\beta[K-k]}{(\alpha+\beta)}$

18 This is a realistic assumption as the representative cannot make any inference about these parameters before having interacted with the responders, and thus does not have any reason to assume that these differ between the responders 
3. for at least two responders $\mathrm{i}=\mathrm{B}, \mathrm{C}$ and $\mathrm{D}$ : $\left(y_{i} \leq y_{A}\right.$ and $\left.y_{i}-k \geq y_{A}-K\right)$ and $\left(y_{i} \leq y_{A}-\lambda\right)$, with

$$
\lambda=\frac{3 \mathrm{k}+\beta[K-k]}{(\alpha+\beta)}
$$

\section{Proof}

Strategy combinations with exactly one responder voting in favor of punishment (which thus lead to nonpunishment) are not an equilibrium if at least two responders are better-off when the representative is punished (and thus the representative is punished).

We assume that $E_{i}$ is the endowment that player i receives before the distribution of the additional resources M. $x_{i}$ is the share of the additional resources M player i obtains and $y_{i}=E_{i}+x_{i}$. Suppose that the representative A proposes the distribution $\left(x_{A}, x_{B}, x_{C}, x_{D}\right)$, with $x_{A}+x_{B}+x_{C}+x_{D}=M$, and $0 \leq x_{i} \leq M,(i=A, B, C, D)$. We now look at the conditions that make a responder's utility higher with punishment than without punishment. The utility of responder B without punishment would then $\mathrm{be}^{19}$ :

$$
\begin{array}{r}
U_{B}^{P O}=y_{B}-\alpha \frac{1}{3}\left[\max \left\{y_{A}-y_{B}, 0\right\}+\max \left\{y_{C}-y_{B}, 0\right\}+\max \left\{y_{D}-y_{B}, 0\right\}\right] \\
-\beta \frac{1}{3}\left[\max \left\{y_{B}-y_{A}, 0\right\}+\max \left\{y_{B}-y_{C}, 0\right\}+\max \left\{y_{B}-y_{D}, 0\right\}\right]
\end{array}
$$

The utility of responder B with punishment would be:

$$
\begin{aligned}
U_{B}^{P l}= & y_{B}-k-\alpha \frac{1}{3}\left[\max \left\{y_{A}-K-y_{B}+k, 0\right\}+\max \left\{y_{C}-k-y_{B}+k, 0\right\}+\max \left\{y_{D}-k-y_{B}+k, 0\right\}\right] \\
& -\beta \frac{1}{3}\left[\max \left\{y_{B}-k-y_{A}+K, 0\right\}+\max \left\{y_{B}-k-y_{C}+k, 0\right\}+\max \left\{y_{B}-k-y_{D}+k, 0\right\}\right]
\end{aligned}
$$

We have the following possible situation $\mathrm{s}^{20}$ :

(a) $y_{B} \leq y_{A}$ and $y_{B}-k \leq y_{A}-K$

(b) $y_{B} \leq y_{A}$ and $y_{B}-k \geq y_{A}-K$

(c) $y_{B} \geq y_{A}$ and $y_{B}-k \geq y_{A}-K$

(d) $y_{B} \geq y_{A}$ and $y_{B}-k \leq y_{A}-K$

Case (a) $U_{B}^{P 1} \geq U_{B}^{P 0}$ if $-k-\alpha \frac{1}{3}\left[-K+y_{A}+k-y_{B}\right] \geq-\alpha \frac{1}{3}\left[y_{A}-y_{B}\right]$

$$
\begin{aligned}
& \Leftrightarrow-k-\alpha \frac{1}{3}[-K+k] \geq 0 \\
& \Leftrightarrow \alpha \geq 3 \frac{k}{K-k}
\end{aligned}
$$

Case (b) $U_{B}^{P 1} \geq U_{B}^{P 0}$ if $-k-\beta \frac{1}{3}\left[-k+y_{B}+K-y_{A}\right] \geq-\alpha \frac{1}{3}\left[y_{A}-y_{B}\right]$

19 We elaborate here the case, where people include their endowment $E_{A}, E_{B}, E_{C}$ or $E_{D}$ in their utility function. However, it might also be that players only take account of the amount to be distributed and not of the final pay-offs. In such a case, the endowment terms have to be removed from all expressions.

20 Note that a responder's preference for punishment does not depend on the inequality vis-à-vis the other responders, as punishment costs are the same for all responders, and consequently punishment does not have any impact on the inequality between responders. The responder's utility depends on whether she faces advantageous or disadvantageous inequality towards the representative before and after punishment. This implies that the conditions as elaborated for responder B equally apply for responders $\mathrm{C}$ and $\mathrm{D}$, who might have different endowments. 


$$
\begin{aligned}
& \Leftrightarrow-3 \mathrm{k}-\beta\left[-k+y_{B}+K-y_{A}\right] \geq-\alpha\left[y_{A}-y_{B}\right] \\
& \Leftrightarrow 3 \mathrm{k}+\beta[-k+K]+\beta\left[y_{B}-y_{A}\right]-\alpha\left[y_{A}-y_{B}\right] \leq 0 \\
& \Leftrightarrow \beta\left[y_{B}-y_{A}\right]+\alpha\left[y_{B}-y_{A}\right] \leq-3 \mathrm{k}-\beta[-k+K] \\
& \Leftrightarrow(\alpha+\beta) \cdot\left(y_{B}-y_{A}\right) \leq-3 \mathrm{k}-\beta[-k+K] \\
& \Leftrightarrow y_{B} \leq y_{A}-\lambda \text { with } \lambda=\frac{3 \mathrm{k}+\beta[K-k]}{(\alpha+\beta)}
\end{aligned}
$$

Case (c) $U_{B}^{P 1} \geq U_{B}^{P O}$ if $-k-\beta \frac{1}{3}\left[-k+y_{B}+K-y_{A}\right] \geq-\beta \frac{1}{3}\left[y_{B}-y_{A}\right]$ $\Leftrightarrow \beta \frac{1}{3}[K-k] \leq-k$

this condition is infeasible as $K>k>0$ and $\beta \geq 0$; in this case the utility with punishment will always be lower than the utility without punishment.

Case (d) this is infeasible because $k<K$

Taking together cases (a), (b), (c) and (d) we come to the conditions as described in this proposition that make that at least two responders are better off when the representative is punished (and thus the representative is punished).

\section{Lemma 1}

If the representative believes that he cannot influence the punishment outcome with his distribution decision, his optimal distribution decision will be:

1. keep all resources if $\beta_{A}<\frac{3}{4}$

2. distribute the resources so that the final income of all players is equalized, if $\beta_{A}>\frac{3}{4}$

\section{Proof}

We will show the case where the representative is punished. The non-punishment case is similar as marginal utilities of changing the shares of the players are the same without punishment ( $\mathrm{K}$ and $\mathrm{k}$ are not dependent on the shares of the players).

The utility of the representative with punishment would be:

$$
\begin{aligned}
U_{A}^{P I}= & y_{A}-K-\alpha_{A} \frac{1}{3}\left[\max \left\{y_{B}-y_{A}-k+K, 0\right\}+\max \left\{y_{C}-y_{A}-k+K, 0\right\}+\max \left\{y_{D}-y_{A}-k+K, 0\right\}\right] \\
& -\beta_{A} \frac{1}{3}\left[\max \left\{y_{A}-y_{B}+k-K, 0\right\}+\max \left\{y_{A}-y_{C}+k-K, 0\right\}+\max \left\{y_{A}-y_{D}+k-K, 0\right\}\right]
\end{aligned}
$$

If the representative cannot influence the punishment outcome, the game reduces to a dictator game. As $\beta_{A} \leq \alpha_{A}$ and $0 \leq \beta_{A}<1$, all responders will receive an equal or lower share than the representative after punishment

$$
U_{A}^{P l}=y_{A}-K-\beta_{A} \frac{1}{3}\left[3 \mathrm{y}_{A}+3 \mathrm{k}-3 \mathrm{~K}-y_{B}-y_{C}-y_{D}\right]
$$


$\frac{\partial U_{A}}{\partial y_{A}}=1-\beta_{A}>0 ; \frac{\partial U_{A}}{\partial y_{B}}=\frac{\partial U_{A}}{\partial y_{C}}=\frac{\partial U_{A}}{\partial y_{D}}=\beta_{A} \frac{1}{3}>0$

$\frac{\partial U_{A}}{\partial y_{A}}>\frac{\partial U_{A}}{\partial y_{B}}$ if $\beta_{A}<\frac{3}{4}$

1. If $\beta_{A}<\frac{3}{4}$ the representative will maximize his/her income by excluding all responders from the resources.

Consequently, $U_{A}^{P 1}=M+E_{A}-K-\beta_{A} \frac{1}{3}\left[3 E_{A}+3 \mathrm{M}-3 \mathrm{~K}-E_{B}-E_{C}-E_{D}+3 \mathrm{k}\right]$

2. If $\beta_{A}>\frac{3}{4}$ the representative will maximize the income of the responders.

Therefore, $y_{A}-K=y_{B}-k=y_{C}-k=y_{D}-k=\frac{1}{4}\left(M+E_{A}+E_{B}+E_{C}+E_{D}-3 \mathrm{k}-K\right)$,

and, $U_{A}^{P I}=\frac{1}{4}\left(M+E_{A}+E_{B}+E_{C}+E_{D}-3 \mathrm{k}-K\right)$

\section{Proposition 2}

If the representative believes that the punishment outcome depends on his distribution decision, the representative's optimal strategy is:

1. If $\beta_{A}>\frac{3}{4}$, the representative equalizes the final income of all players.

2. If $\beta_{A}<\frac{3}{4}$, the 'exclude-all'-strategy is optimal if this strategy and any alternative strategy lead to the same punishment outcome. The 'exclude-all'-strategy is not optimal and instead the 'exclude-one'-strategy is preferred, if the 'exclude-all'-strategy implies punishment whereas the 'exclude-one'-strategy does not and $\left(1-\beta_{A} \frac{4}{3}\right)\left(M-x_{A}\right)<K-\beta_{A}[K-k]$, with $x_{A}<M, x_{A}$ being the representative's share under the 'exclude-one'strategy.

\section{Proof}

1. $\beta_{A}>\frac{3}{4}$ :

According to lemma 1 the representative will equalize the final income of all players if he/she believes that the punishment outcome is independent from his/her distribution decision. If he/she believes that the punishment outcome is dependent on his/her distribution decision, this strategy would still be optimal, as it leads to nonpunishment. Equalizing the final income of all players makes each responder preferring that the representative is not punished.

2. $\beta_{A}<\frac{3}{4}$ :

According to lemma 1 the representative will keep as much as possible to him/herself if he/she believes that the punishment outcome is independent from the distribution. Whether this strategy is still optimal if he/she believes that the punishment outcome is dependent from the distribution, depends on the punishment outcome of this strategy and any alternative strategy. For any other strategy to be preferred to the 'exclude-all'-strategy it must be that only the latter strategy implies punishment. We elaborate this for the 'exclude-one'-strategy: 
$U_{A}($ Exclude - all $)=E_{A}+M-K-\beta_{A} \frac{1}{3}\left[E_{A}+M-E_{B}+k-K+E_{A}+M-E_{C}+k-K+E_{A}+M-E_{D}+k-K\right]$

$U_{A}($ Exclude - one $)=y_{A}-\beta_{A} \frac{1}{3}\left[y_{A}-E_{B}+y_{A}-y_{C}+y_{A}-y_{D}\right] ;$ assume he/she excludes responder B

The exclude-one strategy is preferred above the exclude-all strategy if and only if:

$$
\begin{aligned}
& E_{A}+M-K-\beta_{A} \frac{1}{3}\left[E_{A}+M-E_{B}+k-K+E_{A}+M-E_{C}+k-K+E_{A}+M-E_{D}+k-K\right]<y_{A}-\beta_{A} \frac{1}{3}\left[y_{A}-E_{B}+y_{A}-y_{C}+y_{A}-y_{D}\right] \\
& \Leftrightarrow E_{A}+M-K-\beta_{A} \frac{1}{3}\left[3 E_{A}+3 \mathrm{M}+3 \mathrm{k}-3 \mathrm{~K}-E_{B}-E_{C}-E_{D}\right]<y_{A}-\beta_{A} \frac{1}{3}\left[3 \mathrm{y}_{A}-E_{B}-y_{C}-y_{D}\right] \\
& \Leftrightarrow E_{A}+M-K-\beta_{A} \frac{1}{3}\left[3 E_{A}+3 \mathrm{M}+3 \mathrm{k}-3 \mathrm{~K}-E_{B}-E_{C}-E_{D}\right]<y_{A}-\beta_{A} \frac{1}{3}\left[3 \mathrm{x}_{A}+3 E_{A}-E_{B}-x_{C}-E_{C}-x_{D}-E_{D}\right] \\
& \Leftrightarrow M-K-\beta_{A} \frac{1}{3}[3 \mathrm{M}+3 \mathrm{k}-3 \mathrm{~K}]<x_{A}-\beta_{A} \frac{1}{3}\left[3 \mathrm{x}_{A}-x_{C}-x_{D}\right] \\
& \Leftrightarrow M-K-\beta_{A} \frac{1}{3}[4 \mathrm{M}+3 \mathrm{k}-3 \mathrm{~K}]<x_{A}-\beta_{A} \frac{4}{3} x_{A} \\
& \Leftrightarrow\left(1-\beta_{A} \frac{4}{3}\right) M-K-\beta_{A}[k-K]<\left(1-\beta_{A} \frac{4}{3}\right) x_{A} \\
& \Leftrightarrow\left(1-\beta_{A} \frac{4}{3}\right)\left(M-x_{A}\right)<K-\beta_{A}[K-k], \text { with } x_{A}<M
\end{aligned}
$$

Note that, if $\beta_{A} \geq \frac{3}{4}$ this condition always holds as $K>k$ 